OS SENTIDOS DA PALAVRA AFRO-DESCENDENTE NOS TEXTOS DA MÍDIA: UMA QUESTÃO DE AGENCIAMENTO POLÍTICO

THE MEANINGS OF THE WORD "AFRO-DESCENDANT" IN TEXTS PUBLISHED IN THE MEDIA: A QUESTION OF POLITICAL AGENCY

Sílvia Mara de Melo*

RESUMO: o objetivo deste artigo é apresentar uma análise da palavra afro-descendente, considerando os sentidos desta lexia nos textos da mídia. Também é objeto desta reflexão as acepções das lexias negro e afro-brasileiro, as quais são tomadas dos dicionários de Aulete (1948), Borba (2002; 2004) e Ferreira (1986). Como referencial teórico-metodológico empregaremos as concepções de agenciamento político e domínio semântico de determinação, propostas por Guimarães, o qual enuncia do lugar da semântica da enunciação.

PALAVRAS-CHAVE: língua, agenciamento político, léxico, afrodescendente.

ABSTRACT: The purpose of this paper is to present an analysis of the word "afro-descendant", considering its meanings in texts published in the media. The meanings of the lexemes "black" and "Afro-Brazilian" taken from the dictionaries Aulete (1948), Borba (2002; 2004) and Ferreira (1986), are also analyzed. As a theoretical-methodological framework, it will be used the conceptions of political agency and semantic domain of determination proposed by Guimarães, who enunciates from the place of the semantics of enunciation.

KEY WORDS: language, political agency, lexicon, afro-descendant.

^Unesp Araraquara, doutoranda. Email: smara_melo@hotmail.com 



\section{OS SENTIDOS DA PALAVRA AFRO-DESCENDENTE NOS TEXTOS DA MÍDIA: UMA QUESTÃO DE AGENCIAMENTO POLÍTICO}

\section{Introdução}

A idéia de escrever este artigo surgiu após ter lido um texto de Mário Prata, o qual diz respeito a uma questão de linguagem, na verdade, refere-se à mudança que ocorre na língua. Vamos a ele, para só então começarmos a reflexão que propomos aqui. O texto tem como título $O$ nome das coisas.

O nome das coisas - Mário Prata

Outro dia fui comprar um abajur. A mocinha me olhou e perguntou:

- Luminária?

Eu olhei em volta, tinha uma porção de abajur.

- Não, abajur mesmo, eu disse.

- De teto?

Fiquei olhando meio pasmo para a vendedora, para o teto, para a rua. Ou eu estava muito velho ou ela estava muito nova. No meu tempo - e isso faz pouco tempo - o abajur a gente punha no criado-mudo, na mesinha da sala. E lá em cima era lustre.

- Lustre? 
Descobri que agora é tudo luminária. Passou por spot, virou luminária. Pra mim isso é pior que bandeirinha virar auxiliar de arbitragem e passe (no futebol) chamar-se- agora- assistência. Quem são os idiotas que ficam o dia inteiro pensando nessas coisas? Mudar o nome das coisas? Por que eles não mudam o próprio nome? A mocinha da luminária, por exemplo, se chamava Mariclaire. Desconfio até que já tivesse mudado de nome.

Pra que mudar o nome das coisas? Eu moro numa rua que se chama Rodovia Tertuliano de Brito Xavier. Sabe como se chamava antes? Caminho do rei. Pode? Coisa de vereador com minhoca na cabeça e tio para homenagear. Mas lustres e abajur, gente, é demais. Programação de televisão virou grade. Deve ser para prender o espectador mais desavisado. Entrega em domicílio virou delivery. Agenda de correio, mailing. São os publicitários, os agentes de 'marquetingui'? Quer coisa mais bonita do que criado-mudo? Existe nome melhor para aquilo? Pois agora as lojas vendem mesa-de-apoio. Considerando-se a estratégica posição ao lado da cama, posso até imaginar para que tipo de apoio serve.

Antigamente virava-se santo. Agora vira-se beato, como se já não bastassem todas as carolas beatas que temos por aí. Mudar o nome de deputado para putado ninguém tem coragem, né? Nem de senador para sonhador. Sonhadores da República, não soa bem? A turma dos dez por cento agora se chama lobista! E a palavra não vem de lobo. Mas parece. E por que é que agora as aeromoças não querem mais ser chamadas assim? Agora são comissárias. Não entendo: a palavra comissária vem de comissão, não é? Aeromoça é tão bom e terno como criado-mudo. Pior se as aeromoças virassem moças-de-apoio. Taí uma idéia.

E tem umas palavras que surgem de-repente do nada. Quer ver? : luau. Isso é novo. Quando eu era jovem, se alguém falasse essa palavra ou fosse participar de um lual, era olhado meio de lado. Era pior que tomar vinho rosê. Coisa de bicha, isso de luau. Mas a vantagem de ser um pouco mais velho é saber que o computador que hoje todo mundo tem em casa e que na intimidade é chamado de micro, nasceu com o nome de cérebro-eletrônico. Sabia dessa? E sabia que o primeiro computador, perdão, cérebro eletrônico, pesava 14 toneladas? E que, na inauguração do primeiro, os gênios da época diziam que até o final do século, se poderia fazer computadores de apenas uma tonelada?

Outra palavrinha nova é stress. Pode ter certeza, minha jovem, que, antes de inventarem a palavra, quase ninguém tinha stress. Mais ou menos 
como a TPM. Se a palavra está aí a gente tem de sofrer com ela, não é mesmo? No meu tempo o máximo que a gente ficava era de saco cheio. Estressado, só a turma do luau.

E agora me diga: por que é que em algumas casas existe jardim de inverno e não jardim de verão? E, se você quiser mudar o nome desta crônica para lingüiça, pode. Desde que coloque o devido trema. Também conhecido como dois pinguinhos.

\section{Afro-descendente ou afro-brasileiro?}

A crônica bem humorada de Mário Prata nos faz refletir tanto sobre as mudanças que ocorrem comumente no uso da língua, quanto sobre a criação de palavras novas. Este texto nos fez pensar em algumas palavras que surgiram recentemente, e a que nos chama a atenção, mais particularmente, é afro-descendente. Se afro-descendente é uma palavra que surgiu na boca do povo tem pouco tempo, então que outra palavra era empregada, quando se queria dizer que o sujeito não é de cor branca, sem demonstrar preconceito?

Primeiramente, pretendemos pesquisar a palavra afro-descendente e suas correspondentes, tais como negro e afro-brasileiro nos dicionários. Após examinarmos os sentidos das palavras nos dicionários, pretendemos, em seguida, verificar em quais cenas enunciativas figura a palavra afro-descendente.

Propomos, neste artigo, uma reflexão que busque responder aos seguintes questionamentos:

1) A palavra afro-descendente, a qual figura, certamente, nos textos da mídia, não figura nos dicionários pesquisados. Por esse motivo, a estamos considerando uma palavra nova, a questão que se coloca é por que houve a necessidade de se criar uma palavra nova;

2) Que sentidos afro-descendente adquirem nos textos da mídia?

Negro figura no dicionário como uma raça. Afro-brasileiro, figura como relativo ao Brasil e à África. Afro-descendente não aparece em nenhum dicionário pesquisado.

Afro-descendente não consta nos dicionários, mas se buscarmos os conceitos das partes que compõem essa lexia, temos que, para Borba (2004), afro é: 1 . Próprio dos negros africanos. 2. Relacionado com o que é africano. 
3. De origem africana. Segundo a acepção de Ferreira (1988); descendente é: 1. Que descende. 3. Pessoa que descende de outra ou de uma raça. Dessa formação, afro (Borba) + descendente (Ferreira) resulta afro-descendente, que refere-se ao sujeito que descente da África, da raça africana. Afrodescendente é uma palavra mais abrangente do que afro-brasileiro. Desse modo, podemos afirmar que afro descendente pode estar se referindo a qualquer pessoa de descendência africana, não há nessa lexia nada que a vincule à idéia de nacionalidade brasileira. Já a acepção afro-brasileiro carrega em seu bojo o que diz respeito tanto ao Brasil quanto à África. Isso tudo nos leva a questionar se este sujeito que é afro-descendente não pode ser considerado afro-brasileiro nas condições em que figuram.

Quem é o afro-descendente nas cenas enunciativas em que aparecem? De quem se está falando? Por que não pode ser denominado afro-brasileiro?

\section{Enunciação e agenciamento político}

Para Guimarães (2005), é relevante pensar a questão do político na linguagem ao tratar dos estudos da enunciação. Para ele, "enunciar é uma prática política em um sentido muito preciso".

Não se enuncia enquanto um ser físico, mas enquanto ser afetado pelo simbólico, em um mundo vivido através do simbólico. Segundo Guimarães (2005, p. 16)

[...] o político é um conflito entre uma divisão normativa e desigual do real e uma redivisão pela qual os desiguais afirmam seu pertencimento. Mais importante ainda para mim é que deste ponto de vista o político é incontornável porque o homem fala. $\mathrm{O}$ homem está sempre a assumir a palavra, por mais que esta lhe seja negada.

A noção de político importa na configuração de acontecimento de linguagem, pois o acontecimento de linguagem é um acontecimento político.

O espaço de enunciação também é um espaço político, pois são nos espaços de enunciação que se dá o funcionamento de línguas, que se "dividem", "redividem", "se misturam", "desfazem", "transformam” por uma disputa incessante. Nesses espaços estão os falantes, sujeitos divididos por seus direitos ao dizer e aos modos de dizer.

Há uma relação do sujeito com a língua que é dividida, e a identificação do sujeito se dá por essa relação hierárquica que ele tem com essa língua, o 
que Guimarães denomina de "hierarquia de identidades". Essa divisão distribui desigualmente os falantes segundo os valores dessa hierarquia.

[...] estar identificado pela divisão da língua é estar destinado, por uma deontologia da língua, a poder dizer certas coisas e não outras, a poder falar de certos lugares de locutor e não de outros, a ter certos interlocutores e não outros. (GUIMARÃES, 2005, p. 21)

No embate entre línguas e falantes, o qual se dá nos espaços de enunciação, os falantes são tomados por agenciamentos enunciativos, configurados politicamente. Termo cunhado por Guimarães ao redimensionar a noção de agenciamento coletivo, já proposto por Ducrot e agenciamento enunciativo por Deleuze.

$\mathrm{O}$ agenciamento enunciativo ocorre em espaços particularizados por uma deontologia específica de distribuição dos lugares de enunciação no acontecimento. Assim, nos dizeres de Guimarães (2005, p. 23), "os lugares enunciativos são configurações específicas do agenciamento enunciativo para aquele que fala e para aquele a quem se fala".

Então, não são sujeitos falantes donos de seu dizer que tomam a palavra para si e tem domínio do dizer. É preciso se considerar os lugares constituídos pelos dizeres. Compreender a cena enunciativa é considerar os lugares de funcionamento da língua. Dito de outro modo, para que o locutor se represente como origem do que enuncia, é preciso que seja tomado não como ele próprio, mas como um lugar social de locutor.

Tendo em vista que o conceito de agenciamento político, proposto por Guimarães traz algumas particularidades do que Deleuze propôs como agenciamento enunciativo, retornemos a este último filósofo da linguagem a fim de compreendermos aquilo que Guimarães incorpora e o que acrescenta ao conceito de agenciamento. Lembrando que tal expressão já havia sido empregada por Ducrot como agenciamento coletivo. Temos aqui um percurso interessante dessa palavra que vai de agenciamento coletivo (Ducrot), para agenciamento enunciativo (Deleuze) e agenciamento político (Guimarães).

Para Deleuze, a unidade elementar da linguagem é o enunciado, é a palavra de ordem. Para ele, a linguagem não é transmissão de informação, mas transmissão de palavra funcionando como palavra de ordem, a qual remete, por sua vez, a todo ato que está ligado aos enunciados, uma "pergunta", uma "promessa" são palavras de ordem. 
Uma língua parece se definir pelas constantes fonológicas, semânticas, sintáticas, que coexistem em seus enunciados; o agenciamento coletivo, ao contrário, concerne ao uso dessas constantes em função das variáveis interiores a própria enunciação. (DELEUZE, 1995, p. 25).

Um agenciamento comporta dois segmentos: um de conteúdo, outro de expressão. Agenciamento maquínico (de corpos, mistura de corpos reagindo uns sobre os outros); agenciamento coletivo de enunciação (de atos e de enunciados), transformações incorpóreas sendo atribuídas aos corpos.

Parafraseando Deleuze, entendemos agenciamento maquínico como as "máquinas", ou seja, são as instituições concretas, tais como a escola, a igreja, o tribunal, a imprensa (mídia); já agenciamento coletivo como conjunto de signos ou de enunciação, os quais partem dessas "máquinas".

Dito de outro modo, compreendemos que o agenciamento maquínico está para as instituições assim como o agenciamento enunciativo está para o enunciado.

Tendo em vista que resgatamos os conceitos propostos por Deleuze a fim de situarmos a concepção de agenciamento político de Guimarães, voltemos a ele. Para Guimarães (2007, p. 205), “o acontecimento de enunciação se dá sempre num espaço de divisão de línguas, se dá sempre num espaço político". Para ele, mesmo no espaço onde se dá uma língua, tal como a língua portuguesa, as "línguas" são diferentes em seus falantes porque o espaço de enunciação distribui as "línguas" diferentemente. Os sujeitos falantes de uma língua não são as pessoas na atividade físico-fisiológica, mas sujeitos constituídos pelos espaços de enunciação e pelos falantes.

Diferentemente de Ducrot, o qual trata do agenciamento coletivo como um "acordo" de um grupo, em Guimarães o agenciamento político é afetado politicamente porque se dá em espaços de enunciação. E o agenciamento político de enunciação deve ser compreendido na cena de enunciação, a qual é definida por Guimarães (2007, p. 207), como: "modo de constituição dos lugares de dizer constituídos pela funcionamento da língua". É inerente à cena enunciativa dividir e distribuir os lugares de enunciação.

Desse modo, o agenciamento político deve ser concebido em um espaço de enunciação e em uma cena enunciativa. 


\section{Afro-descendente nas cenas enunciativas: textos midiáticos}

\section{Texto 1}

Cultura africana na música:

Desde o ano de 2003 foi promulgada a lei 10.639, que instituiu a obrigatoriedade da inclusão da história e cultura africana a afro-brasileira dentro dos currículos escolares. Esta lei veio como tentativa de dar visão a um outro lado da história do afro-descendente, que geralmente é contada de forma distorcida, na perspectiva de grupos hegemônicos.

Sendo que mais de 50\% da população é afro-descendente (dados do senso do IBGE do ano 2000), negligenciar suas contribuições culturais é ignorar a identidade brasileira. Estas contribuições estão presentes na culinária, na música, nas festas, na religiosidade e até mesmo em nosso vocabulário.

Com o intuito de valorizar a imagem do afro-descendente e de sua cultura, desenvolveu-se o presente projeto, partindo do estudo de nomes afro-descendentes importantes dentro do samba brasileiro. Dessa forma, pretende-se mostrar uma imagem positiva do negro e de sua cultura, levando os alunos a conhecerem as raízes de nossa música, para que possam desta maneira valorizar o afro-descendente.

(excerto extraído do site www.unesc.net/projeto_cap/index)

Neste texto, podemos seguramente afirmar que se está falando do afrobrasileiro, do descendente afro que vive no Brasil. Aqui as palavras afrodescendente, afro-brasileiro e negro têm os mesmos referentes, ou seja, está se falando do negro brasileiro. Não há uma distinção entre essas três palavras.

No $1^{\circ}$ parágrafo, afro-descendente funciona como um elemento anafórico de afro-brasileiro, para não repetir esta expressão, emprega-se aquela.

No $3^{\circ}$ parágrafo, a impressão que se tem é de que negro apresenta a mesma função anafórica, pois ele vem substituir a expressão afro-descendente, a qual fora utilizada duas vezes no período anterior.

Notamos aqui que não há uma distinção quanto ao emprego dessas três palavras: negro, afro-brasileiro e afro-descendente. Elas são empregadas como sinônimos e com uma função coesiva apenas.

No segundo parágrafo desta mesma cena, o locutor toma afro-descendente como sujeito que possui uma identidade brasileira. Seguramente, aqui, há a comprovação de que está se referindo ao afro-brasileiro. 
Se tomarmos as acepções dos dicionários, certamente poderemos afirmar que a lexia afro-descendente é desnecessária, isso se estamos pensando do ponto de vista da significação apenas, já que temos afro-brasileiro nos dicionários e tal lexia condiz com o sentido que se pretende atribuir.

Se afro-brasileiro condiz com o sentido que se quer atribuir ao indivíduo negro, se é uma palavra dicionarizada, voltamos a questionar, por que se empregar neste mesmo espaço afro-descendente?

\section{Texto 2}

Arapongas vai eleger sua mais bela afro-descendente

A mais bela afro-descendente da cidade de Arapongas (norte do Paraná) será escolhida na próxima sexta-feira (24) no concurso "Beleza Negra", promovido pela secretaria municipal de cultura lazer e eventos (sede).

O evento que vai reunir 11 candidatas com idade entre 15 e 25 anos, será realizado no anfiteatro Oduvaldo Vianna Filho (Vianinha), a partir das $20 \mathrm{~h}$. A promoção faz parte das apresentações culturais que marcaram o "Dia Nacional da Consciência Negra", comemorado no dia 20 de novembro.

Para Reinaldo J. Souza um dos coordenadores do concurso, o objetivo é despertar na população a valorização da miscigenação cultural brasileira.

(excerto extraído de www.bonde.com.br)

No mesmo espaço enunciativo em que ocorre afro-descendente, se dá também as expressões "Beleza negra", "Dia Nacional da consciência negra" e "miscigenação cultural brasileira". Tendo em vista que a cena está tratando de um concurso de beleza que ocorrerá em uma cidade do Brasil, no estado do Paraná, seguramente é de mulheres negras, brasileiras a que se está referindo. E se ainda tomarmos os adjetivos "negra", "nacional" e "brasileira", sabemos que é de negros que vivem no Brasil que trata o texto.

Aqui tal como na cena 1, a lexia preferida é afro-descendente e tal como na cena 1, entendemos que a lexia afro-brasileira daria conta do sentido que se pretende atribuir ao negro. No entanto, "afro-descendente" persiste. 


\section{Texto 3}

Afro-descendentes: desafios no mercado de trabalho

[...] Pesquisas importantes, como o mapa da população negra no mercado de trabalho, publicado pelo Dieese em 1999, já mostravam como questões como a precarização das condições de trabalho, o trabalho informal, o trabalho infantil, $o$ desemprego e a exclusão social resultante da modernização tecnológica afetavam mais os afro-descendentes do que os outros grupos sociais. Além disso, a desigualdade racial também pode ser observada na estrutura familiar do Brasil.

[...] Neste cenário, acreditamos ser fundamental a adoção de políticas públicas, na forma de ações afirmativas, que possibilitem aos afro-descendentes brasileiros condições favoráveis para uma inserção positiva no mercado de trabalho.

[...] Segundo os dados apresentados, a renda média de um trabalhador não-negro é 105\% superior a de um trabalhador negro.

(excerto extraído de www.consorciodajuventuderj.org.br)

Neste texto, as lexias afro-descendente e negro convivem num mesmo cenário, em uma relação anafórica, ora negro remete a afro-descendente ora afro-descendente remete a negro. Também aqui não há uma distinção de sentido ao se empregar um ou outro, ambos referem-se ao negro que vive no Brasil.

Nesta cena 3, chama a atenção o parágrafo em que surge a expressão "afro-descendente brasileiro". Por que empregar tal expressão se apenas afro-brasileiro corresponde ao sentido que se quer atribuir ao texto? Afro-descendente brasileiro é uma redundância se considerarmos que existe a expressão afro-brasileira. Essa redundância pode ocorrer por dois motivos, ou o sujeito desconhece a lexia afro-brasileira, e ou é agenciado por essa nova palavra que surgiu na mídia, e, portanto, a emprega.

Afro-brasileiro figura como uma das entradas do prefixo afro em todos os dicionários examinados. Para que um sujeito ou algo possa ser considerado afro-brasileiro, é condição que se tenha uma relação entre dois países, o Brasil e a África.

Aulete (1948) - Afro-brasileiro: africano e brasileiro.

Ferreira (1986) - Afro-brasileiro: relativo ou pertencente à África e ao Brasil. O negro brasileiro. 
Borba (2002) - Afro-brasileiro: relacionado ou pertencente à África e ao Brasil simultaneamente.

Borba (2004) - Afro-brasileiro: relacionado ou pertencente à África e ao Brasil simultaneamente.

Talvez a resposta para nossos questionamentos iniciais, esteja na questão envolvendo o agenciamento enunciativo. Como o locutor é agenciado pelo espaço de enunciação, ele emprega a palavra "afro-descendente" porque está num espaço em que a expressão está sendo utilizada. Não há da parte dos locutores dos textos que examinamos um discernimento quanto às diferenças de sentido entre negro, afro-descendente e afro-brasileiro. Por esse motivo, afro-descendente figura nos textos como termos anafóricos ou como sinônimos.

Em relação à lexia negro, os dicionários a definem das seguintes formas:

Aulete (1948) - Homem de raça negra, preto.

Ferreira (1986) - Diz-se do indivíduo de raça negra. Escravo. Homem, pessoa, indivíduo.

Borba (2002) - Da ou relativo à raça. Na ou da raça. Pessoa da etnia. * no discurso direto é usado para marcar a pretensa superioridade do branco.

Borba (2004) - Diz-se da pessoa de pele com pigmentação escura. Típico da raça de cor escura. ${ }^{\star}$ forma carinhosa de dirigir-se a alguém.

Negro, em todos os dicionários, figura como raça, como indivíduo de pele escura, sem ter alguma relação com o país africano. No nosso entender, afro-brasileiro é um termo mais específico porque é preciso que haja uma ligação entre os dois países, já negro é um termo mais genérico, pois se refere à raça ou ao sujeito de pele com pigmentação escura, pode estar se referindo a um sujeito de outra descendência, que não a africana. Isso significa que há nos dicionários tanto um termo específico quanto um termo mais geral quando se deseja mencionar um sujeito de raça negra.

Entendemos que não se deve atribuir à palavra a responsabilidade de todo o significado, pois o sentido se dá no acontecimento. Nas acepções de Borba acerca da palavra negro, 2002, ele afirma que negro pode ser empregado para marcar a pretensa superioridade do branco, no dicionário de 2004, acrescenta que negro também pode ser uma forma carinhosa de dirigir-se a alguém. Aqui não é uma questão de valor polissêmico de uma palavra, pois que a cena enunciativa constrói significados. 


\section{Domínio semântico de determinação (DSD) da palavra afro-des- cendente nos textos 1, 2 e 3.}

Guimarães (2007) constitui o conceito de (DSD), domínio semântico de determinação, para representar o sentido das palavras e, segundo seu ponto de vista, uma semântica não pode deixar de tomar como elemento fundamental a referência, a relação com algo fora dela.

O DSD leva em consideração a relação de sentido que as palavras têm com outras palavras e elas significam as relações de determinação semântica que se constituem no acontecimento enunciativo.

Nas palavras de Guimarães (2007, p. 80)

[...] dizer qual é o sentido de uma palavra é poder estabelecer seu DSD. E isso só pode ser feito a partir do funcionamento nos textos em que aparece. Outra coisa importante, um DSD é construído pela análise das relações de uma palavra com as outras que a determinam em textos em que funciona. Deste modo podemos dizer o que significa uma palavra num certo texto, num conjunto de textos relacionados por algum critério que os reúna: do mesmo autor, sobre um certo assunto, de um certo momento.

Um DSD é a análise de uma palavra dentro de um campo específico, podendo ser um texto, um conjunto de textos. E Guimarães apresenta os seguintes símbolos para a construção do DSD: $(\vdash ;-\uparrow ;, \perp,=$ determina); (一, indica oposição, antonímia).

As palavras têm sua história de enunciação, elas não estão em nenhum texto como um princípio sem qualquer passado. (GUIMARÃES, 2007, p. 81).

Parafraseando Guimarães, iremos neste momento conceituar a reescrituração, tendo em vista que é um conceito elaborado pelo lingüista ao adotar uma posição teórico-metodológica em relação à unidade de análise: a palavra.

A reescrituração que Guimarães denomina operação de predicação refere-se a uma expressão que se reporta a outra, empregando diversos procedimentos, ou seja, pode-se tomar uma expressão para negá-la, retomá-la, para redizê-la com outras palavras, pode-se ainda expandi-la, condensá-la etc. A reescrituração pode ocorrer por: repetição, substituição, elipse, expansão, condensação e definição.

Dependendo da relação que a palavra mantém com as outras palavras que as reescrituram dentro de um texto ou de um conjunto de textos, elas 
podem adquirir características muito particulares, por esse motivo os procedimentos de reescrituração se dão por sinonímia, especificação, desenvolvimento, generalização, enumeração, totalização.

Levando-se em consideração a palavra afro-descendente nos textos 1, 2, 3 procuramos encontrar seu DSD (domínio semântico de determinação).

A palavra afro-descendente no texto 1 se reescreve por repetição três vezes, ocorrendo uma reescrituração por sinonímia com a palavra negro, no último parágrafo do texto, também se dá reescrituração por sinonímia com identidade brasileira.

DSD

Identidade brasileira

$\top$

Afro-descendente - negro

No texto 2, ocorre a reescrituração por repetição uma vez apenas da palavra afro-descendente.

No texto 3, afro-descendente se reescreve por repetição uma vez, por sinonímia duas vezes com a palavra negro e por expansão com a palavra afro-descendente brasileiro uma vez. E há também uma relação de antonímia com a palavra outros grupos sociais.

DSD

Negro - Afro-descendente $\dashv$ afro-descendente brasileiro

outros grupos sociais

Como figura afro-descendente levando-se em conta o conjunto dos três textos: T1, T2 e T3.

DSD

negro

identidade brasileira $\vdash$ Afro-descendente $\dashv$ afro-descendente brasileiro

outros grupos sociais 


\section{Considerações Finais}

Com base nas reflexões dos três textos que examinamos, chegamos a algumas considerações.

Entendemos que a palavra afro-descendente é empregada porque o sujeito que está no espaço de enunciação é agenciado pela mídia. Vimos que não há uma diferença de sentido entre as palavras afro-descendente e negro nas cenas enunciativas examinadas.

Comumente, a palavra afro-descendente desliza para negro.

A palavra fora da enunciação não tem sentido, o sentido se dá nas cenas enunciativas. Portanto, a palavra afro-descendente, no nosso entender, não ameniza uma prática social cristalizada, ou seja, o preconceito. Pois o preconceito não está na palavra negro ou preto, mas pode estar nas cenas enunciativas.

\section{Referências Bibliográficas}

AULETE, Caldas. Dicionário de língua portuguesa. Lisboa. $3^{\text {a }}$ ed., 1948.

BORBA, Francisco da Silva. Dicionário de usos do português do Brasil. São Paulo: Ática, 2002.

. (Org.). Dicionário Unesp do português contemporâneo. São Paulo: Unesp, 2004.

DELEUZE G. \& GUATARRI F. Mil Platôs: Capitalismo e Esquizofrenia. São Paulo: Editora 34, 1995.

FERREIRA, Aurélio Buarque de Holanda. Novo Dicionário da língua portuguesa. São Paulo. 2a ed., Editora Nova Fronteira, 1986.

GUIMARÃES Eduardo. Semântica do Acontecimento. Campinas: Pontes, $2^{a}$ ed., 2005.

. Texto e Argumentação: um estudo de conjunções do português. $4^{\text {a }}$ ed. Campinas: Pontes, 2007.

GUIMARÃES, E. \& MOLLICA, Maria Cecília (Orgs.). A palavra forma e sentido. Campinas: Pontes, 2007.

PRADO, Heloisa. Arapongas vai elegir sua mais bela afro-descendente. Disponível em: <http://www.bonde.com.br>. Acesso em: 07 de setembro de 2007. 
SOUZA, Andréa Alcione. Afro-descendente: desafios no mercado de trabalho. Disponível em: <http://www.consorciodajuventudederj.org.br> . Acesso em: 10 de agosto de 2007.

UNESC - Prometo Pesquisa-Formação. Cultura africana na música. Disponível em: http:// <www.unesc.net/projeto>. Acesso em: 07 de setembro de 2007.

Recebido em 25 de novembro de 2007

Aceito em 27 de fevereiro de 2008 